\title{
Effect of Vitamin E on the Anti-Coagulant Response
}

\author{
Ludivine Lechevretel ${ }^{1}$, Raoul Santucci ${ }^{1}$, Mélanie Burgin-Noll ${ }^{1}$, Cécile Caille ${ }^{2}$, Eric Marchioni ${ }^{3}$, Françoise Pieri ${ }^{1}$, \\ Audrey Jourdil ${ }^{2}$, Franck Couturier ${ }^{1}$ and Patrice Challan-Belval ${ }^{2}$
}

${ }^{1}$ Service de Pharmacie-Stérilisation, France

${ }^{2}$ Service de Médecine Interne 1. Groupe Hospitalier Saint Vincent, France

${ }^{3}$ Equipe de Chimie Analytique des Molécules BioActives, France

Submission: February 03, 2017; Published: March 10, 2017

*Corresponding author: Ludivine Lechevretel, Service de Pharmacie-Stérilisation, France, Tel: 388458194; Email: 1.lechevretel@ghsv.org

\begin{abstract}
Aim: Fluindione is the most used Vitamin $\mathrm{K}$ antagonists in France. It has been sparsely studied and few interactions have been reported with food sources. This case reveals a significant rise in INR when fluindione was associated to fatty acid (palmitic/oleic/linoleic acid $2 \mathrm{~g} / \mathrm{day}$ ) or vitamin E $(1 \mathrm{~g} /$ day $)$.

Presentation of Case: A 80-year-old male (weight $74 \mathrm{~kg}$, body surface area $1.91 \mathrm{~m}^{2}$ ) with a history of severe allergic drug eruption documented with low molecular weight heparins, vancomycin, rifamycin and netromycin was treated and stabilized (International Normalized Ratio (INR) = 3.5) with fluindione (10 to $15 \mathrm{mg}$ once per day) for cardiovascular risks due to a mechanical aortic heart valve and an aortic tube. During hospitalization, the patient stopped eating dietary supplements containing fatty acids and vitamin E (Day 0), and then, presented an imbalance of the INR (Day 2: INR = 3.5 / Day 2: INR = 1.2). An unexpected anticoagulant response (INR up 1.1 to 3.7) on fluindione was observed after administration on vitamin $\mathrm{E}$ (1000mg once per day) for the same patient.
\end{abstract}

Analyzes performed by high-performance liquid chromatography on dietary supplements reveal low dose of $\alpha / \gamma / \delta$-tocophérol $(22 / 0.5 / 0.3$ $\mathrm{mg} /$ day respectively) and unexpected high dose of fatty acid (2 $\mathrm{g}$ opd containing 13/22/56\% of palmitic/oleic/linoleic acid respectively). No genetic variability in the VKORC1 and CYP2C9 could be identified. The patient plasma concentration of vitamin K was 328 ng/L (normal value: $150-900 \mathrm{ng} / \mathrm{L})$.

Discussion and Conclusion: Fatty acids and/or vitamin E associated could increase significantly the vitamin K antagonist therapy effect.

Keywords: Fluindione; Fatty acids; Vitamin E; Tocopherol; Coagulation; VKORC1; Palmitic acid; Oleic acid; Linoleic acid; Vitamin K antagonists

Abbreviations: VKA: Vitamin K Antagonists; INR : International Normalized Ratio; VKOR : Vitamin-K Epoxyde Reductase

\section{Introduction}

Vitamin $\mathrm{K}$ antagonists (VKAs) are the leading cause of hospitalization due to iatrogenic drugs. VKAs based anticoagulant therapies are associated with large dose response variability. This paper reports the first case of increased prothrombin time developed in a patient to which fluindione was administered after eating dietary supplements (pumpkin seed oil, saw palmetto Florida, ginseng root extract and tribulus fruit extract) and/or vitamin E.

\section{Presentation of Case}

A 80 -year-old male (weight $74 \mathrm{~kg}$, body surface area 1.91 $\mathrm{m}^{2}$ ) with a history of severe allergic drug eruption documented with low molecular weight heparins, vancomycin, rifamycin and netromycin was treated and stabilized (International Normalized Ratio (INR) = 3.5) with fluindione (10 to $15 \mathrm{mg}$ once per day) for cardiovascular risks due to a mechanical aortic heart valve and an aortic tube. During hospitalization, the patient stopped eating the dietary supplements (Day 0) and then presented an imbalance of the INR (Day 2: INR = 3.5 / Day 2: INR = 1.2). INR interfering factors were eliminated (poor adherence, new therapy, dietary changes...). To ensure efficient anticoagulation considering his severe allergy, a treatment with danaparoid 2000 UI twice per day was then initiated.

The patient was suspected to be resistant to treatment with VKAs. The city physician was contacted. He declared that the fluindione doses needed to achieve the INR target ranged from 40 to $60 \mathrm{mg}$ per day prior to taking dietary supplements. However no genetic variability in the VKORC1 and CYP2C9 could be identified. His plasma concentration of vitamin K was 328 ng/L (normal value: 150-900 ng/L). 


\section{Global Journal of Pharmacy \& Pharmaceutical Sciences}

\section{Results}

Fluindione dose was gradually increased: $15 \mathrm{mg}$ to Day 2 (Day 5 and Day 6: INR = 1.1), $20 \mathrm{mg}$ on day 6 (Day 8: INR $=1.3$ ) and $25 \mathrm{mg}$ at Day 8 (Day 10: INR = 1.4). As estimation based on the product-label of dietary supplements totalized $645 \mathrm{mg}$ of equivalent $\alpha$-tocopherol, a treatment with vitamin $\mathrm{E}$ ( $\alpha$-tocopherol) was started on day 10 at $500 \mathrm{mg}$ once per day (Day 12: INR = 1.8) and increased at day 12 to $1000 \mathrm{mg}$ opd (Day 15: $\mathrm{INR}=2.3$ / Day 18: INR = 2.9 / Day 24: INR = 3.7 / Day 29: INR $=3.6$ ) without changing the fluindione dose (25 mg opd) (Figure 1). One month after initiating the vitamin E treatment, the plasma concentration of $\alpha$-tocopherol (41 $\mu$ mol/L [16-35 $\mu \mathrm{mol} / \mathrm{L}])$, vitamin $\mathrm{K} 1$ (324 ng/L [150-900 ng/L]) and fluindione (2.6 mg/L [2-6 mg/L]) were in normal range. Analyzes performed by high-performance liquid chromatography on dietary supplements reveal low dose of $\alpha / \gamma / \delta$-tocophérol (22/0.5/0.3 mg/day respectively) and unexpected high dose of fatty acid ( $2 \mathrm{~g}$ opd containing $13 / 22 / 56 \%$ of palmitic/oleic/ linoleic acid respectively) (Figure 1).

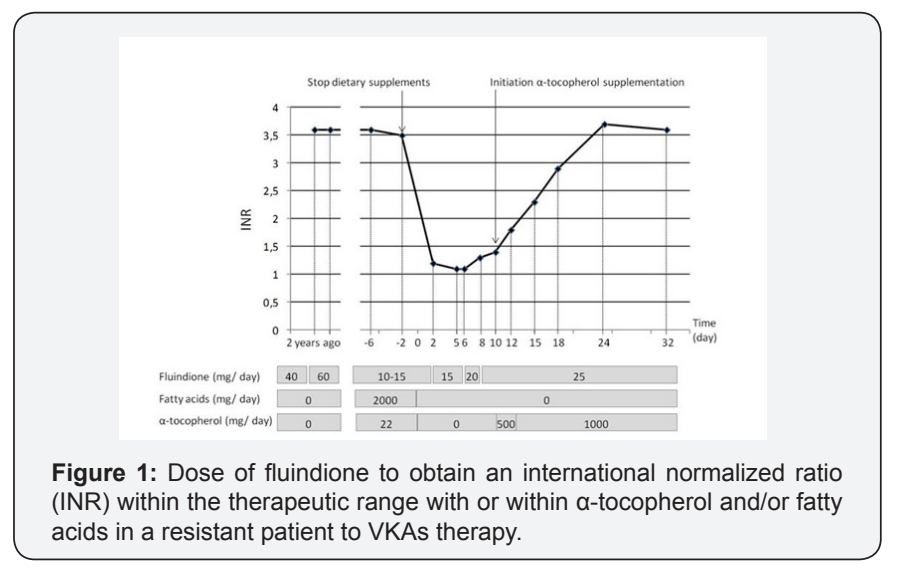

\section{Discussion}

Fluindione, an indanedione derivative, is the most used VKAs in France. It has been sparsely studied and few interactions have been reported with food sources. Vitamin E is used in many food sources, dietary supplements (pumpkin seed oil, palm oil, corn oil, safflower oil, almond, honey-roasted...) and is used as a food preservative (E306-309) for its antioxidant properties [1]. The prevalence of complementary and alternative medicine (CAM) with vitamin $\mathrm{E}$ was reported by $24.2 \%$ of all patient taking warfarin and $71 \%$ of those who used potentially interacting CAM [2]. The vitamin E supplementation has an anticoagulant effect in the presence of low vitamin $\mathrm{K}$ intake or VKAs treatment in animal and human cells studies [3]. But clinical studies in human could not associate the vitamin E exposure with an increase of the risk of self-reported bleeding or out of range INR [2,4]. Only one case was reported with an increase prothrombin time in a patient who was taking warfarin with self administration of vitamin E. This case demonstrates enhanced reduction of the levels of vitamin K-dependent coagulation factors without warfarin plasmatic level modification during the period of vitamin E intake [5].

In parallel, warfarin treated subjects didn't change their INR with $400 \mathrm{mg}$ opd of vitamin E [6]. Interpretation of the available information on vitamin E-warfarin interaction is difficult because nearly all of them are based on in-vitro data, animal studies, individual case report or study on few patients. This report is the first one indicating an increasing effect of the fluindione anticoagulant efficiency by $\alpha$-tocopherol. The effects of fatty acids on hemostasis are controversial. It has been difficult to show convincing effect of unsaturated fatty acids [7]. Studies have demonstrated contradictory effects of oleic and linoleic acid consumption on coagulation. The mechanism of action of oleic and linoleic acid is not completely understood, but a dual anti-platelet and anticoagulant effect on Factor VII has been proposed [8-11]. We report the first case of increasing the therapeutic effect of fluindione by these fatty acids.

Recently, genetic variants (C1) of vitamin K epoxyde reductase (VKOR), the pharmacologic target of VKAs, have been associated to resistance to VKAs [12]. As VKORC1 genotype strongly affected anticoagulation induced by fluindione, we emit the hypothesis that it should affect the vitamin $\mathrm{E}$ and fatty acids anticoagulation effect. But this mutation could not be found in our patient.

\section{Conclusion}

This case reveals a significant rise in INR when fluindione was associated to dietary supplements and/or vitamin E. Patients undergoing anticoagulation therapy, pharmacist and physicians should pay special attention to this potential interaction.

\section{References}

1. Robert L Martin (2010) Center for Food Safety and Applied Nutrition. Food and Drug Administration pp 1-166.

2. Leung VW, Shalansky SJ, Lo MK, Jadusingh EA (2009) Prevalence of use and the risk of adverse effects associated with complementary and alternative medicine in a cohort of patients receiving warfarin. Ann Pharmacother 43(5): 875-81.

3. Glynn RJ, Ridker PM, Goldhaber SZ, Zee RY, Buring JE (2007) Effects of random allocation to vitamin E supplementation on the occurrence of venous thromboembolism: report from the Women's Health Study. Circulation 116(13): 1497-503.

4. Meydani SN, Meydani M, Blumberg JB, Leka LS, Siber G, et al. (1997) Vitamin E supplementation and in vivo immune response in healthy elderly subjects: A randomized controlled trial. JAMA 277(17): 13801386.

5. Corrigan JJ, Marcus FI (1974) Coagulopathy associated with vitamin E ingestion. JAMA 230(9): 1300-1301.

6. Kim JM, White RH (1996) Effect of vitamin E on the anticoagulant response to warfarin. Am J Cardiol 77(7): 545-6.

7. Knapp HR (1997) Dietary fatty acids in human thrombosis and hemostasis. Am J Clin Nutr 65(5): 1687-1698. 
8. Turpeinen AM, Mutanen M (1999) Similar effects of diets high in oleic or linoleic acids on coagulation and fibrinolytic factors in healthy humans. Nutr Metab Cardiovasc Dis 9(2): 65-72.

9. Benito P, Nelson GJ, Kelley DS, Bartolini G, Schmidt PC, et al. (2001) The effect of conjugated linoleic acid on platelet function, platelet fatty acid composition, and blood coagulation in humans. Lipids 3(3)6: 221-227.

10. Hunter KA, Crosbie LC, Horgan GW, Miller GJ, Dutta-Roy AK (2001) Effect of diets rich in oleic acid, stearic acid and linoleic acid on postprandial haemostatic factors in young healthy men. Br J Nutr 86(2): 207-215.
11. Allman-Farinelli MA, Hall D, Kingham K, Pang D, Petocz P, et al. (1999) Comparison of the effects of two low fat diets with different alpha-linolenic: linoleic acid ratios on coagulation and fibrinolysis. Atherosclerosis 142(1): 159-168.

12. Lacut K, Ayme-Dietrich E, Gourhant L, Poulhazan E, Andro M, et al. (2012) Impact of genetic factors (VKORC1, CYP2C9, CYP4F2 and EPHX1) on the anticoagulation response to fluindione. $\mathrm{Br} \mathrm{J}$ Clin Pharmacol 73(3): 428-436.

Your next submission with Juniper Publishers will reach you the below assets

- Quality Editorial service

- Swift Peer Review

- Reprints availability

- E-prints Service

- Manuscript Podcast for convenient understanding

- Global attainment for your research

- Manuscript accessibility in different formats

( Pdf, E-pub, Full Text, Audio)

- Unceasing customer service

Track the below URL for one-step submission https://juniperpublishers.com/online-submission.php 